\title{
RELAÇÕES DE CONFIANÇA E SUA INSTRUMENTALIZAÇÃO NO CONTROLE DE DOCENTES EM IES PRIVADAS ${ }^{1}$
}

\author{
Bárbara Novaes Medeiros ${ }^{2}$ \\ Marcus Vinicius Soares Siqueira ${ }^{3}$
}

http://dx.doi.org/10.1590/1413-2311.241.90087

\begin{abstract}
RESUMO
O objetivo deste estudo é analisar, sob um enfoque crítico e reflexivo, a confiança e sua instrumentalização no discurso de gerentes como modalidade de controle de docentes em Instituições de Ensino Superior (IES) privadas, à luz da ideologia gerencialista em tempos de avanço neoliberal. É uma pesquisa exploratória-descritiva, com contribuições da análise crítica do discurso (FAIRCLOUGH, 2016), da ideologia gerencialista e da sociologia clínica, realizada em um município de Minas Gerais com doze (12) gerentes de três (3) IES privadas. Os resultados revelaram que a comunicação e a expressão da confiança nas IES é instrumentalizada no discurso gerencial para eufemizar as relações de controle e dominação, por meio de estratégias ideológicas como: a criação de uma relação mais próxima com os docentes em prol do engajamento (por meio da gestão de afetos); a responsabilização do docente pela sua contratação e permanência (por meio do recalcamento da postura crítica); e a busca pela identificação total deles com a IES (por meio da idealização da instituição). Desse modo, há a inserção do docente em uma massa acrítica, sob os auspícios do poder

\footnotetext{
${ }^{1}$ Recebido em 05/02/2019; aprovado em 03/04/2019.

2 Universidade de Brasília (UNB) - Programa de Pós-Graduação em Administração da Faculdade de Administração, Contabilidade, Economia e Gestão de Políticas Públicas (FACE); Brasília - DF (Brasil) barbaranovaesmedeiros@hotmail.com

3 Universidade de Brasília (UNB) - Programa de Pós-Graduação em Administração da Faculdade de Administração, Contabilidade, Economia e Gestão de Políticas Públicas (FACE); Brasília - DF (Brasil) marc-vs@uol.com.br
} 
gerencialista, que o coloca como um fiel servo da IES e não apenas dela, mas da lógica que o aprisiona afetivamente.

Palavras-chave: Confiança. Discurso Gerencial. Controle. Ideologia Gerencialista. IES privadas.

\title{
RELATIONSHIPS OF TRUST AND ITS INSTRUMENTALIZATION IN THE CONTROL OF TEACHERS IN PRIVATE HEIS
}

\begin{abstract}
The objective of this study is to analyze, under a critical and reflexive approach, the trust and its instrumentalization in the discourse of managers as a modality of control of teachers in Private Higher Education Institutions (HEI) in the light of the managerialist ideology in times of neoliberal advancement. It is an exploratory-descriptive research, with contributions the critical analysis of discourse (FAIRCLOUGH, 2016), managerialist ideology and clinical sociology, fulfilled in a municipality of Minas Gerais with 12 managers of 3 private HEIs. The results revealed that the communication and expression of trust in HEIs is instrumental in managerial discourse to euphemize the relations of control and domination, through ideological strategies such as: creating a closer relationship with teachers in favor of engagement (through management of affections); the teacher's responsibility for their hiring and permanence (through the repression of the critical posture); and the search for their total identification with the HEI (through the idealization of the institution). Thus, there is a teaching insertion in an uncritical mass, under the auspices of the managerial power that poses as a faithful servant of HEI and not only of it, but of a logic that imprisons him affectively.
\end{abstract}

Keywords: Trust. Management Discourse. Control. Managerial Ideology. Private HEI.

\section{RELACIONES DE CONFIANZA Y SU INSTRUMENTACIÓN EN EL CONTROL DE DOCENTES EN IES PRIVADAS}

\section{RESUMEN}


El objetivo de este estudio es analizar, bajo un enfoque crítico y reflexivo, la confianza y su instrumentalización en el discurso de gerentes como modalidad de control de docentes en Instituciones de Enseñanza Superior (IES) privadas a la luz de la ideología gerencialista en tiempos de avance neoliberal. Es una investigación exploratoria-descriptiva, con las contribuciones del análisis crítico del discurso (FAIRCLOUGH, 2016), de la ideología gerencialista y de la sociología clínica, realizada en un municipio de Minas Gerais con 12 gerentes de 3 IES privadas. Los resultados revelaron que la comunicación y expresión de la confianza en las IES es instrumentalizada en el discurso gerencial para eufemizar las relaciones de control y dominación, por medio de estrategias ideológicas como: la creación de una relación más cercana con los docentes en favor del compromiso (por medio de la gestión de afectos); la responsabilización del docente por su contratación y permanencia (por medio de la represión de la postura crítica); y la búsqueda por la identificación total de ellos con la IES (por medio de la idealización de la instituición). De este modo, hay la inserción del docente en una masa acrítica, bajo los auspicios del poder gerencialista que lo coloca como un fiel siervo de la IES y no sólo de ella, sino de una lógica que lo aprisiona afectivamente.

Palabras clave: La confianza. Discurso Gerencial. Control. Ideología Gerencialista. IES privadas.

\section{INTRODUÇÃO}

As Instituições de Ensino Superior (IES) privadas possuem dupla natureza, pedagógica e administrativa, o que pode conferir o caráter paradoxal do ensino como mercadoria dentro da lógica capitalista de competição em tempos neoliberais (ARANTES, 2015; MEDEIROS, 2017; XIMENES, 2015). Tal fator, somado a hegemonização da ideologia gerencialista à serviço do poder gerencial, legitimador de pensamentos objetivistas, utilitaristas e funcionalistas sob justificativas racionais em uma sociedade paradoxante - a qual afirma liberdade em um mundo de restrições e controles cada vez mais sofisticados -, influenciam o exercício da docência no ensino superior e a dimensão subjetiva de docentes (ARANTES, 2015; GAULEJAC, 2007, 2017; MEDEIROS, 2017; XIMENES, 2015), a partir de "injunções paradoxais que inibem a razão, favorecem a adesão e a aceitação da 
racionalidade instrumental" (GAULEJAC, 2007, p. 144). As injunções paradoxais atuam de modo a encobrir as contradições no mundo do trabalho.

Para isso, utilizam-se de mecanismos sutis de controle psíquicos na gestão do afetivo, como o estímulo à criação de vínculos subjetivos entre o trabalhador e a organização (ENRIQUEZ, 1990; FARIA; SCHMITT, 2007; SIQUEIRA, 2009). Esses vínculos são construídos com base no "sentimento de pertença, filiação, possibilidade de realização de desejos, reconhecimento entre outros" (FARIA; SCHMITT, 2007, p. 23). Afinal, hoje tudo se gere (GAULEJAC, 2007), atitudes, comportamentos, modo de pensar e agir, emoções, amor, vínculos e até mesmo a expressão da confiança.

Nas relações interpessoais entre gerentes e trabalhadores, a confiança é instrumentalizada em prol do engajamento dos trabalhadores nas organizações, a fim de se estabelecer relações de empatia e proximidade. Busca-se o reforço do laço afetivo com o trabalhador, seu comprometimento afetivo, evidenciando-se que o que é bom para a organização, é bom também para o trabalhador - para a sua permanência (empregabilidade) e o progresso (ENRIQUEZ, 1999; FREITAS, 2000; GAULEJAC, 2007). Nesse estímulo do amor, a comunicação e expressão da confiança ganha um "manto de bom mocismo" (FREITAS, 2000). Desse modo, o trabalhador lança-se nas mãos do objeto amado (ENRIQUEZ, 1999), ao ponto de não perceber ou até mesmo perceber, mas se deixa levar pela adesão voluntária à IES, não apenas como forma de obediência, mas como devoção (GAULEJAC, 2007; PAGÈS et al. 1987).

Esse processo por parte da gestão é considerado por Faria e Meneghetti (2007b) como sequestro da subjetividade no interior da lógica competitiva a partir da dominação subjetiva. Isso quer dizer que há um aprisionamento psicológico do trabalhador a uma rede real e imaginária de relações de trabalho. É assim que as organizações mediam contradições no seio organizacional e exercem o controle social de forma eficaz (FARIA; SCHMITT, 2007). Nas IES, entre gerentes e docentes isso tende a não ser diferente.

É importante ressaltar que nos mainstreams organizacionais, a confiança tem sido trabalhada em perspectiva utilitarista e funcionalista, como fator preponderante para o alcance de resultados organizacionais. A confiança, nesses termos, é entendida por Diniz e Marconatto (2011, p. 54) como um "um mecanismo substituto de aparatos formais destinados a controlar e fiscalizar a ação dos agentes em relacionamento, seja ele do tipo patrãoempregado, firma-firma, colegas de trabalho, cliente-fornecedor"; como elemento fundamental para se alcançar os resultados organizacionais (FERNANDES, 2014); e para eficiência dos contratos de trabalho (ZANINI; MIGUELES, 2014). 
É contingencial, que trabalhadores obsessivamente apaixonados confiam mais em sua organização e sentem-se mais confortáveis para assumir tarefas desafiadoras (HO; ASTAKHOVA, 2017); a liderança e confiança explicam a propensão ao risco extremo para as operações (ZANINI; SANTOS; LIMA, 2015); é fundamental na liderança gerencial para construção e manutenção de um ambiente de trabalho que passe confiança (KODISH, 2014); com ela, supervisores cultivam psicologicamente o comprometimento dos funcionários (KIDRON, 2018); há uma correlação positiva entre as dimensões de clima organizacional e confiança (ANDRADE; FISCHER; STEFANO, 2015); há influência das políticas de gestão de pessoas na confiança do colaborador e no bem-estar no trabalho (HORTA; DEMO; ROURE, 2012).

Todavia, o debate crítico acerca do discurso e da confiança sob os auspícios do controle psíquico é escasso. Isto posto, pretende-se neste estudo, analisar, sob um enfoque crítico e reflexivo, a confiança e sua instrumentalização no discurso de gerentes como modalidade de controle de docentes em IES privadas, à luz da ideologia gerencialista em tempos de avanço neoliberal.

A intenção deste trabalho ${ }^{4}$ é desmistificar esses pressupostos ideológicos na comunicação e expressão da confiança com intenção de ocultar o controle psíquico nas suas práticas sociais no contexto das IES, ancorando-se para isso na abordagem teóricametodológica da Análise Crítica do Discurso (ACD) (FAIRCLOUGH, 2016) de doze (12) gerentes - todos os gerentes que lidam com docentes - em três (3) IES privadas, em um município localizado no estado de Minas Gerais sob orientação da abordagem qualitativa e exploratória-descritiva.

O corpus desta pesquisa partirá do texto falado e transcrito pelos gerentes em entrevista semiestruturada e em profundidade, que é parte da prática discursiva e uma amostra da prática social deles nesse contexto. A ACD visa explorar relações opacas e obscuras nas ligações entre discurso, ideologia e poder entre práticas discursivas, eventos e textos; e nas estruturas sociais e culturais, relações e processos mais amplos (FAIRCLOUGH, 1993). Isso auxiliará a compreender como, sob os auspícios do poder gerencialista, o docente se coloca como fiel servo da IES e não apenas dela, mas de uma lógica que o aprisiona afetivamente.

Assim, a principal contribuição teórica deste estudo reside em utilizar-se de elementos constituintes da análise crítica do discurso, ideologia gerencialista e da sociologia clínica, esta

\footnotetext{
${ }^{4} \mathrm{O}$ presente trabalho foi realizado com apoio da Coordenação de Aperfeiçoamento de Pessoal de Nível Superior - Brasil (CAPES) - Código de Financiamento 001.
} 
última, mais preocupada em entender o indivíduo, suas relações de trabalho e seus processos de subjetivação (NUNES; SILVA, 2018), a fim de se compreender a confiança sob outro olhar, pautado na desnaturalização das características ideológicas do poder gerencialista.

O estudo reconhece como oportuna a investigação crítica da comunicação e expressão da confiança no discurso gerencial com fins de controle psíquico. Em função disso, avança o conhecimento propagado desde Pagès et al. (1987) sobre as políticas e as práticas de gerenciamento da subjetividade, e contribui para mudar o modo como as relações de trabalho entre gerentes e docentes são subjetivadas. A partir dessa consciência é que surgem as possibilidades de resistência e mudança social nas relações (FAIRCLOUGH, 1999).

Logo após esta introdução, tem-se a fundamentação teórica, que abordará o discurso gerencial e o avanço da ideologia gerencialista em IES sob ótica da análise crítica do discurso. Posteriormente, serão apresentados os procedimentos metodológicos, discutidos os resultados sob à ótica téorico-metodológica da ACD (FAIRCLOUGH, 2016). Por fim, serão realizadas as considerações finais.

\section{DISCURSO GERENCIAL E O AVANÇO DA IDEOLOGIA GERENCIALISTA EM IES SOB ÓTICA DA ANÁLISE CRÍTICA DO DISCURSO}

Historicamente, o Ensino Superior brasileiro é marcado por sua expansão desde os anos 90, o que não significa que houve universalização do ensino, mas sim o aumento expressivo de instituições de cunho privado sob princípios mercantilistas, em um cenário macro de avanço do neoliberalismo e da globalização, impulsionado por práticas gerencialistas competitivas e pela adoção de metodologias oriundas do mercado capitalista, que mercantilizam a educação (SEVERINO, 2009).

Nesse contexto, o gerenciamento se torna mais caprichoso (HANLON, 2016) e opera por meio de práticas que hegemonizam a ideologia gerencialista no trabalho de docentes e nas relações sociais instituindo uma "nova linguagem" e um "novo discurso", que contempla ordens de discurso gerencialistas em detrimento do discurso emancipatório (ARANTES, 2015). Como dito por Gaulejac (2007, p. 269) "é sem dúvida no campo da educação que a pressão da ideologia gerencialista é mais evidente e mais inquietante", principalmente para submeter seu sistema educativo às normas gerencialistas.

Um exemplo disso, é a instrumentalização do cunho social das IES, ou seja, a função educativa/formativa dessas instituições tem sido utilizada pela gestão gerencialista como mais um dos instrumentos sutis de controle para a mobilização do docente quanto ao maior 
comprometimento e engajamento no e com o trabalho e na IES (MEDEIROS, 2017). A tentativa gerencial é simbolizar por meio da promoção do discurso gerencial o modo de trabalho como "uma missão", a fim de que o docente se sinta como "construindo o mundo, enquanto na realidade ele está sendo produzido, investido por todas as partes e modelado até no seu interior" (PAGÈS et al., 1987, p. 172).

É uma espécie de encantamento pela "missão", para que a doação à IES aconteça de modo integral. Essa é uma forma de impactar a subjetividade e canalizar a energia libidinal (PAGÈS et al., 1987) do docente à dedicação com o trabalho e à IES. Como dito por Hanlon (2016, p. 14), “especula-se que a subjetividade será empurrada para endosso cada vez maior das relações sociais capitalistas" (HANLON, 2016, p. 14). Isso não é diferente, por exemplo, nas organizações do terceiro setor, onde as práticas decorrentes do gerencialismo chocam-se também com os valores humanistas, causando como dito por Salimon e Siqueira (2012, p. 648), "conflitos de racionalidade e intrapsíquicos", como por exemplo, a perda de identidade profissional. É uma lógica muito próxima.

Esse processo de perda identitária e despersonalização - em sua reformulação para atender o mercado (HANLON, 2016) -, ocorre de modo sutil. Os gerentes propagam a obediência à execução das tarefas organizacionais, alinhadas ao seu próprio interesse político (de permanência e ascensão na IES privada, por mais que ocupe um cargo de confiança) e aos ideais organizacionais conforme a lógica gerencialista. Um dos papéis fundamentais do gerente nos últimos dois séculos tem sido o disciplinamento e a docilização do trabalhador por meio de permanente mobilização subjetiva em direção à constituição do sujeito empreendedor (MORO; AMADOR, 2015). O gerente mostra o caminho a ser seguido pelo trabalhador, auxiliando-o no "processo de 'apego" à organização (SIQUEIRA, 2009, p. 87), a fim de inspirá-lo a levar adiante os projetos da empresa, "cujo nome deve inspirar 'orgulho e confiança"” (GAULEJAC, 2007, p. 118).

O docente tende a acreditar que pode confiar no gerente, e que este último compartilha da mesma preocupação com a eficiência do ensino e com a transmissão do conhecimento com qualidade tanto quanto ele. Mas nem sempre na prática isso ocorre. Quando ocorre, por assim dizer, se dá em via de mão única na medida em que o objetivo gerencial na IES privada é outro e por mais que o docente saiba dessas intenções, principalmente, de quão frágil é nesse laço de confiança - e que quando quebrar, tão logo ele é substituído por outro -, ele se lança no jogo (FREITAS, 2000). Mas, qual seria o motivo?

Pontua-se aqui questões políticas e para isso parte-se do pressuposto que a confiança, sob olhar crítico é compreendida neste trabalho como modalidade de se embrenhar na 
subjetividade, nas emoções, nas representações que o docente faz do seu trabalho, e do modo como se entrega ao objeto amado, aquele que não apenas o sustenta, mas que ele se identifica e se realiza. Logo, quando aprofunda-se nestas questões, percebe-se a ocultação de relações de poder, controle e dominação - do que não pode ser expresso - típicas da ideologia gerencialista (ENRIQUEZ, 1990, 2001; GAULEJAC, 2007; SIQUEIRA, 2009). Por sua vez, essa ideologia é focada no "excesso de trabalho, produtivismo e competitividade", sob pressupostos funcionalistas e utilitaristas, contrária ao "trabalho emancipatório, autônomo e libertador" (ARANTES, 2015, p. 293). Acúmulo de tarefas e funções, uso excessivo das tecnologias, exigência de produtividade, flexibilização são alguns dos fatores que afastam o docente do seu papel formador o que precarizam o seu trabalho, tornando-o um recurso à serviço da gestão gerencialista (FRANCHINI et al., 2016; GAULEJAC, 2007, 2017).

A confiança é tão instrumentalizada nessa relação (e manipulada) que quando se investiga o não-dito, percebe-se que o comprometimento vai muito além de assumir responsabilidade, chega a ser uma dedicação da vida (ENRIQUEZ, 1990). A expressão da confiança, vista deste modo, tem como intenção fortalecer os laços amorosos para o docente sentir-se dependente da IES, ao ponto de não conseguir mais se desligar dela.

A promoção da confiança, nesse sentido, utiliza um imaginário que nutre o ideal comum entre a organização e seus trabalhadores para que eles se ajustem ao que é proposto (SIQUEIRA, 2009). Assim, a tendência é que as representações que o docente faz de si e da organização se confundam, pois o docente confiará de tal forma na IES que tenderá a assumir a identidade dela para sua vida. Neste caso, uma das intenções da organização é ser parceira do indivíduo e com isso aumentar o seu poder nesse processo de autopersuasão (SIQUEIRA, 2009), de convocação subjetiva do trabalhador aos preceitos e ideais do capital (MORO; AMADOR, 2015).

É assim que gerentes "fazem uso da gestão do afetivo que se soma às outras formas de controle organizacional" (SIQUEIRA, 2009, p. 20), ou seja, tendem a influenciar as estruturas psicológicas de docentes "pela identificação total ou expressão de confiança" (ENRIQUEZ, 1990, p. 286). Essas categorias exploradas desde os estudos de Freud sobre identificação, imaginário e recalcamento - que não deixa emergir sentimentos contrários à organização - são essenciais para conferir inteligibilidade a cena organizacional (MOTTA, 1991). Elas são formas de mobilizações psicológicas para reforçar a adesão não só individual, mas coletiva para que os indivíduos levam a diante o propósito organizacional (PAGÈS et al., 1987). Isso favorece à adesão livre e voluntária em uma sociedade ávida pelos imperativos do 
desempenho em todas as esferas da vida social (FACAS; GHIZONI, 2018; GAULEJAC, 2007).

Desse modo, como servos dedicados, os docentes são alimentados pela organização sequestradora - que se apropria das "atividades psíquicas, emocionais e afetivas dos sujeitos individuais ou coletivos que a compõem" (FARIA; MENEGHETTI, 2007b, p. 50) - e tendem a não se apropriar da realidade que os cerca, ficando à mercê do que lhe é oferecido quanto a crenças e valores produzidos e propagados em âmbito da ideologia gerencialista. "É através das sutilezas do dito no que não é dito e da ação de seres únicos e indispensáveis para a organização que se pode perceber o sequestro da subjetividade do trabalhador" (FARIA; MENEGHETTI, 2007b, p. 56).

Há sequestro da subjetividade quando a organização visa conquistar a confiança do docente na marca institucional em função do que ela pode representar para ele (empregabilidade, ascensão, vantagens concedidas, identidade, entre outros), assim como na promessa de reconhecimento (FARIA; MENEGHETTI, 2007b; MOTTA, 1991). Isso fará o indivíduo acreditar fielmente que está trabalhando no melhor lugar e que dele não deverá se desvincular, de modo a assumir um ideal de comprometimento e competitividade, que faz com que se considere como parte da organização. Ele então se apropria do discurso de excelência e eficácia, pronto para desempenhos excepcionais no interior da lógica capitalista (FACAS; GHIZONI, 2018).

Deve-se crer que quem ama, se vincula e confia, pois "o vínculo pressupõe uma relação de cumplicidade" (FARIA; SCHMITT, 2007, p. 33). Esse amor e dedicação do docente à organização e às pessoas chaves, o conduz reciprocamente ao dele com relação à si próprio. Neste caso, seu ego imaginário encontra satisfação para os seus desejos (MOTTA, 1991), que está na base de sua constituição: suas pulsões (FARIA; SCHMITT, 2007). Acrescenta-se que esse amor à organização pode moldar a forma como o indivíduo define ontologicamente seu papel organizacional e as instituições em si mesmas, assim como mudar a sua identidade (TASSELLI, 2018).

Com isso, a organização pretende ser vista confiantemente como "o lugar onde o trabalho, a convivência e os laços fraternos se juntam de forma entusiasmada e prazerosa" (FREITAS, 2000, p. 14), "como sendo o local de satisfação do desejo" (SIQUEIRA, 2009, p. 84), “como uma imensa máquina de dar prazer ao indivíduo" (PAGÈS et al., 1987, p. 164), como uma "deusa mãe a ser adorada, algo como uma nova Medéia que devora aqueles que não se rendem à sua vontade absoluta (MOTTA, 1991, p. 11). 
Para tal, utiliza-se do discurso gerencial, compreendido neste estudo como dispositivo de informação, comunicação e principal meio para difusão da ideologia gerencialista, de crenças, pensamentos e visão distorcida da organização (GAULEJAC, 2007). Por meio do discurso, os gerentes conseguem produzir e propagar uma dimensão ideológica de ideias, valores e sentimentos (formais ou ocultos, explícitos ou implícitos, falado ou escrito, nas imagens e nos meios de comunicação internos) por trás das estratégias de gestão (FARIA; MENEGHETTI, 2007a; GAULEJAC, 2007), "não deixando que o indivíduo se conscientize das políticas da empresa e das contradições sociais que subentendam" (PAGÈS et al., 1987, p. 86), "em virtude de princípios bastante suspeitos no plano moral-prático" (DEJOURS, 2001, p. 72).

O discurso, nesse sentido, é produção ideológica da gestão gerencialista (PAGÈS et al., 1987), "prefere a adesão voluntária à sanção disciplinar, a mobilização à obrigatoriedade, a incitação à imposição, a gratificação à punição, a responsabilidade à vigilância" (GAULEJAC, 2007, p. 199). Enquanto produção ideológica, tem como base o discurso científico de modo a racionalizar e justificar sua produção e promoção, que ora apresenta-se distorcida, sem distorção, mas manipulada para ser usado em uma lógica específica (DEJOURS, 2001).

Promover esse discurso nas IES apela não somente ao desenvolvimento de características do gerente, como saber ouvir seus subordinados, comunicar-se bem e ser habilidoso nas relações interpessoais, mas também com a capacidade de suscitar em si e nos outros o espírito empreendedor (MORO; AMADOR, 2015, p. 207). Relembrando o governo de si, a prática gerencial associada ao poder gerencialista, o autogerenciamento na busca de alto desempenho e a busca de mediação como postulado por Gaulejac (2007) desde Pagès et al. (1987) a respeito do papel do manager.

A prática social do manager nos espaços organizacionais é relacionada à conseguir levar o outro - docente - à ações a partir da mobilização afetiva empreendida. E isso não tem implicações apenas aos demais trabalhadores - docentes, mas também ao próprio gerente, "uma vez que este se constrói como líder a partir de inúmeras prescrições sobre o que saber, o que fazer e, especialmente, o que ser, para colocar em funcionamento junto aos seus subordinados os mesmos mecanismos pelos quais é subjetivado" (MORO; AMADOR, 2015, p. 207). Desse modo, o que ele propaga em seu discurso e ajuda a colocar em funcionamento também incide sobre si, ou seja, as regras do jogo que ele ajuda a operar são as mesmas às quais ele está submetido, o que muda é o impacto, por vezes diferente. 
O manager, mais que qualquer outra pessoa dentro da organização absorve para si fortemente a contradição capital/trabalho, sob a obsessão pela rentabilidade financeira, que lhe ocupa a mente cotidianamente. Torna-se alienado por desempenho na busca de fazer sempre mais pela excelência e qualidade total, e para conquistar tudo isso junto aos subordinados, é especialista em linguagem dupla e em institucionalização de padrões culturais, se apresenta como oráculo da necessidade, mas, é de fato um profissional com capacidade de encobrir crenças e ideologias. Ele tem o poder para determiná-las e reproduzilas entre os indivíduos e grupos. É empreendedor, assume riscos, decide, resolve diariamente problemas complexos. Coloca todas as suas habilidades a serviço da rentabilidade. Prefere muito mais a ação interessada, de modo que os indivíduos são colocados na condição de objetos, medidos de acordo a sua utilidade. Essencialmente, o manager é ofuscado pelo desejo de conquista e de ganhar sempre em todas as situações. Para isso, brinca com o amor, com a identificação e expressão da confiança entre os seus subordinados utilizando-se do discurso do amor e da parceria para persuadi-los (ENRIQUEZ, 1990, 2001; GAULEJAC, 2007; MOTTA 1993 [1979]; PAGÈS et al. 1987; SIQUEIRA, 2009).

Considerando que as relações entre eventos individuais concretos e práticas sociais ocorrem relativamente de modo durável e estável, como por exemplo, no caso do controle do amor, por meio da gestão do afetivo, da idealização e da expressão de confiança (ENRIQUEZ, 1990), tem-se que a ordem do discurso nesse espaço representa as práticas discursivas no modo como significam a prática social particular - discurso -, no uso da linguagem característica à esse espaço escolar por meio de entrevista - gênero -, nos modos de identificação de si mesmo dentro desse espaço escolar - estilo (FAIRCLOUGH, 1993). A ideologia entra nessa ordem a partir de elementos produzidos, promovidos e articulados no discurso (FAIRCLOUGH, 1999).

Nesse sentido, a abordagem teórica e metodológica da ACD nas sociedades contemporâneas entende o uso da linguagem como uma forma de prática discursiva em uma prática social, na qual o discurso está inserido (FAIRCLOUGH, 1999). Por meio da análise crítica do discurso, é possível uma virada social, crítica e histórica, que possibilita identificar e compreender relações sociais, possíveis estruturas ideológicas e facetas do discurso, e como elas moldam a natureza da prática discursiva, sob estratégias ideológicas de ocultação e omissão do controle, poder e dominação (FAIRCLOUGH, 1993; 2016). Afinal, o discurso contribui para a criação e constante recriação das relações, sujeitos, e objetos que compõe o mundo social tanto para sustentar quanto para minar as relações de poder (FAIRCLOUGH, 1999). 
O uso social e a utilidade da análise crítica do discurso contribuem para que haja mudança nas organizações contemporâneas, uma vez que o discurso é um meio de luta para que seja alcançado o consenso na sociedade civil (FAIRCLOUGH, 1993; 2016). Como dito por Melo (2009, p. 14), “os analistas da ACD devem formular pesquisas que exerçam ações de contrapoder e contraideologia, práticas de resistência à opressão social".

Utilizar-se da ACD sob pressupostos de Fairclough (2016) é essencial para resistência e mudança, desde que sejam observadas as condições apontadas pelo autor como a necessidade do método de análise multidimensional - tridimensional (texto, prática discursiva e prática social); multifuncional - que contribua para modificar o conhecimento, as relações sociais e as identidades sociais; histórico - que focalize as construções estruturais do texto e sua constituição como ordens do discurso a longo prazo; e crítico - para mostrar o que está oculto, com intenção de poder intervir e favorecer a mudança em uma realidade social. Assim, a ACD é um rico elemento para se compreender criticamente as organizações, sob esse universo paradoxal cheio de recomendações, procedimentos, injunções, expectativas que compõem o trabalho e suas relações pela lógica utilitária e funcional (GAULEJAC, 2007).

\section{METODOLOGIA}

Este estudo caracteriza-se como exploratório-descritivo, baseado na abordagem qualitativa. O objetivo é analisar, a partir de enfoque crítico e reflexivo, a confiança e sua instrumentalização no discurso de gerentes como modalidade de controle de docentes em Instituições de Ensino Superior (IES) privadas, à luz da ideologia gerencialista em tempos neoliberais. Com esse intuito, optou-se por realizar a pesquisa em uma cidade localizada em Minas Gerais - por refletir um cenário de expansão do Ensino Superior privado, a partir de entrevistas gravadas e posteriormente transcritas ipsis litteris com o apoio do software gratuito Express Scribe Transcription ${ }^{\circledR}$, que reduziu a velocidade das falas para melhor compreensão no momento de transcrição. Após a utilização do software, foi realizada uma revisão completa da transcrição.

Para a realização das entrevistas, utilizou-se de um roteiro semiestruturado e em profundidade aplicado com doze (12) gerentes de três (3) IES privadas - quatro (4) gerentes em cada IES -, sendo sete (7) mulheres e cinco (5) homens, com formação mínima de especialização completa, entre 30-59 anos, ocupantes de cargos, como gerentes de campus/unidade, gerente de recursos humanos, coordenadores de curso, entre outros. A maioria dos indivíduos possuía experiência anterior em docência e em cargos de gerência. 
Nesta pesquisa, os entrevistados foram nomeados de forma fictícia como por exemplo, entrevistado(a) 1, para preservar suas respectivas identidades.

A escolha das três (3) IES se deu de forma intencional, já que são as IES que mais ofertam cursos no nível superior na cidade, sendo, portanto, concorrentes entre si no mercado de ensino privado. Caracteristicamente, são IES privadas de grande porte, possuem fins lucrativos, contam com mais de 500 pessoas em seu quadro de funcionários (entre docentes e demais trabalhadores), além de possuírem mais de 5 mil alunos, cada uma delas.

A análise de dados, dos pontos críticos no discurso professado pelos gerentes que constituem o corpus desta pesquisa, foi realizada a partir da ACD proposta por Fairclough (2016), devido o autor considerá-la como uma abordagem teórico-metodológica importante para pesquisas críticas que investigam aspectos ideológicos do discurso, principalmente quando estão naturalizadas nas práticas discursivas do "senso comum", a fim de contribuir para a manutenção das relações de poder.

Magalhães (2016, p. 11) reforça que o pensamento de Fairclough propõe uma análise profunda não apenas do "papel da linguagem na reprodução das práticas sociais e das ideologias, mas também seu papel fundamental na transformação social”. Essa originalidade é o que justifica a escolha da ACD como orientação teórica e metodológica deste estudo.

É importante destacar que em Fairclough (1999, p. 73), “a linguagem é uma forma material de ideologia, e a linguagem é investida por ideologia”. Em Althusser, disfarça sua natureza ideológica. Em Gramsci, torna-se "bom-senso" (FAIRCLOUGH, 1999). No seu aporte teórico, o Fairclough (2016) considera que o uso da linguagem como discurso é modo de ação, representação, significação, com implicação dialética na estrutura social, uma vez que constitui o social e, é também por ele constituído na construção de identidades, relações sociais e sistema de conhecimentos e crenças.

Com fins de tratar o discurso e suas conexões com a prática social, Fairclough (2016, p. 22) propôs um modelo de análise tridimensional para a $A C D$, afirmando que qualquer "evento discursivo (isto é, qualquer exemplo de discurso) é considerado simultaneamente como um texto, um exemplo de prática discursiva e um exemplo de prática social". Neste estudo, a análise textual ou descrição, que cuida da análise linguística do texto, priorizará quatro critérios: vocabulário, gramática, coesão e estrutura textual, com pretensão de identificar possíveis estruturas ideológicas da instrumentalização da confiança no discurso gerencial. A análise da prática discursiva ou "texto" e "interação", que cuida dos processos de produção e interpretação textual, buscará identificar estratégias discursivas de comunicação e expressão da confiança utilizadas pelos gerentes, a fim de interpretar a confiança no controle 
psíquico de docentes em IES, priorizando para isso três aspectos: força dos enunciados, coerência dos textos e intertextualidades. A análise da prática social, que cuida dos interesses da análise social, focará em perceber como as práticas sociais constroem e são construídas a partir dos discursos professados pelos gerentes em âmbito da ideologia gerencialista nas IES.

Ressalta-se que essa divisão proposta - da análise tridimensional -, tem fins pedagógicos, e neste estudo, não irá obedecer a uma sequência rígida, focará principalmente na análise discursiva da prática social à luz da ideologia gerencialista e da sociologia clínica - por ter como objeto a análise do social, a partir das articulações entre os determinismos sociais e psíquicos; o sujeito (nas ciências, humana e social) e; a abordagem clínica (não com fins terapêuticos, mesmo que ocorram) (NUNES; SILVA, 2018) -, a fim de clarificar as contradições vivenciadas nas relações de trabalho entre gerentes e docentes.

O corpus desta pesquisa será analisado a partir de categorias apreendidas e classificadas em torno de um sentido comum. Foram identificadas três categorias: (i) "é quase liderança carismática" - evidenciando como os gerentes buscam estreitar os laços afetivos com os docentes a fim de canalizar a energia deles para o alcance dos objetivos; (ii) "então a primeira coisa que tem que haver dentro de uma de uma instituição deste tamanho, é confiança" - demonstrando a confiança como uma condição fundamental para a contratação e permanência dos docentes na IES, responsabilizando-os pelas suas ações, desempenho e permanência; (iii) "ele vai levar a bandeira, vestir a camisa" - clarificando as mobilizações psicológicas do docente rumo à adesão voluntária - com dedicação e amor à organização -, a partir do chamamento para "vestir a camisa" da IES, partindo do pressuposto de que quem veste a camisa, confia na IES e entrega-se subjetivamente com amor a ela e aos seus ideais. A seguir, os resultados serão apresentados conforme cada categoria.

\section{ANÁLISE DOS RESULTADOS}

\section{1 "É QUASE LIDERANÇA CARISMÁTICA"}

Essa categoria de análise traz enunciados discursivos dos gerentes (modos de representação do discurso gerencial), que demonstram como eles buscam por meio da confiança estabelecer laços afetivos com os docentes para conquistar à adesão aos objetivos organizacionais das IES privadas. A pretensão é que não haja barreiras entre eles e que a acessibilidade, liberdade e o "sentimento de igualdade", que mitifica a ideia de hierarquia de 
poder - características do poder gerencialista -, sejam hábito nessas IES conforme exemplificado nas verbalizações a seguir:

Os professores têm a liberdade, tem a minha sala lá, então eles entram, eles conversam, marca o horário. Então, é muito próximo por você ter vindo dele (Entrevistado 2).

Então, apesar de comungar no mesmo espaço da direção, o meu papel é tá, como eu falei assim, bom, como eu falei assim, "eu tô no 'chão da fábrica', eu tô". É tipo isso (Entrevistado 2).

Então eu faço hábito de ir todos os dias na sala de professores na hora do intervalo pra poder estabelecer esse contato com o professor ehhh ehhh mais assim, imagino que 80, 90\% vão, se fizer uma pesquisa, vão salientar aí que eu sou uma pessoa acessível, e que isso eu faço muita questão de ser (Entrevistada 3).

É quase liderança carismática (Entrevistada 5).

O entrevistado 2 faz uso do vocábulo "liberdade" para expressar que não há barreiras entre ele (gerente) e o docente. A "sala" é um indicativo dessa liberdade, do uso social comum do docente e gerente, indo além de uma característica de propriedade privada do gerente. "Muito" nesse caso, está intensificando a palavra "próximo", que significa "perto de", chamando atenção para o nível de proximidade que o gerente deseja expressar quando se refere ao relacionamento que mantém com os docentes, tendo em vista que anteriormente também foi docente na instituição. Na sua segunda fala o entrevistado 2 por meio da conjunção conclusiva "então", busca exprimir seu entendimento acerca do seu papel gerencial dizendo que "apesar" de estar na direção, o seu papel é estar no "chão de fábrica". Esse excerto evidencia que o gerente entende que estar na direção não é estar no "chão de fábrica". Há limites entre o estratégico e o operacional, mas por outro lado, como estratégia de ação para estabelecer relacionamento de confiança com os docentes e geri-los por meio do controle afetivo, vai contra isso na sua prática social (ENRIQUEZ, 1990; 1999; SIQUEIRA, 2009). "É tipo isso" (Entrevistado 2). Desse modo, há uma teia de controle via docilização do docente, por meio de uma permanente mobilização subjetiva para favorecer esse processo de apego à IES (MORO; AMADOR, 2015; MOTTA, 1991; SIQUEIRA, 2009).

A fala da entrevistada 6, corrobora com essa proposição, uma vez que a gestão de afetos no estabelecimento de relacionamento entre gerentes e docentes é um "hábito" para a gerente, a fim de criar o imaginário coletivo de ser "uma pessoa acessível" aos docentes (ENRIQUEZ, 1990, 1999; SIQUEIRA, 2009). A gerente ainda enfatiza com o advérbio de 
intensidade "muito", o quanto faz questão de ser vista como uma pessoa acessível pelos docentes. O pensamento da entrevistada 5 só clarifica que esse processo "é quase liderança carismática", ou melhor, foca muito nos afetos e nas emoções para estabelecer relações de confiança (ENRIQUEZ, 1990, 1999; SIQUEIRA, 2009). Desse modo, compreende-se que a gerente tende a exercer sua liderança por meio do poder de seduzir os docentes e captá-los à dedicação ao trabalho (ENRIQUEZ, 1990, 1999; SIQUEIRA, 2009). E por que não dizer que esse carisma é um comportamento característico do poder gerencialista em organizações sequestradoras da subjetividade? (FARIA; MENEGHETTI, 2007b).

A partir desses trechos, percebe-se uma preocupação dos gerentes quanto à prática da gestão de afetos, uma vez que precisam se "colocar" ao lado dos docentes em vez de tomar partido da empresa, ou seja, precisam transparecer isso aos docentes a fim de conquistarem maior engajamento e fortalecerem ainda mais os vínculos subjetivos (FARIA; SCHMITT, 2007). Esse tipo de gestão por afeto tende a garantir um trabalhador mais engajado, com mais confiança na figura e no discurso do gerente (ENRIQUEZ, 1990, 1999; PAGÈS et al., 1987). Nesse sentido, o carisma pode ser um indicativo de como gerentes brincam com o afeto do amor, identificação e expressão da confiança com os seus subordinados para persuadi-los à dedicação ao trabalho pelo vínculo subjetivo da parceria (ENRIQUEZ, 1990, 2001; FARIA; SCHMITT, 2007; GAULEJAC, 2007; PAGÈS et al. 1987; SIQUEIRA, 2009).

Desse modo, pode-se inferir que a confiança constrói relações interpessoais e, é também construída a partir do vínculo que os gerentes estabelecem com os docentes - função dialética do discurso -, na visão de Fairclough (2016). Por estar imbricada na função dialética do discurso do gerente, tende à instrumentalização a favor do controle de docentes a partir das estratégias discursivas empenhadas para a criação e constante recriação das relações, sujeitos, e objetos que compõe o mundo social nesse espaço escolar. Neste caso, visa sustentar ainda a relação de poder (FAIRCLOUGH, 1999), colaborar com a adesão voluntária visando "engajamento total para o sucesso da empresa" (GAULEJAC, 2007, p. 110), a partir do despertamento do espírito empreendedor de si (MORO; AMADOR, 2015).

Nota-se que é com a sutileza da aproximação, da demonstração de apoio, que o gerente se fortalece com a confiança recebida pelo docente para impor tarefas e desafios consoantes com seu interesse próprio e das IES (SIQUEIRA, 2009). Essa mesma confiança construída nessa "parceria" coloca esse superior na posição de exemplo a ser seguido e de forma "prazerosa" pretende a união de laços "fraternos" "pela identificação total ou expressão de confiança" no campo organizacional das IES (ENRIQUEZ, 1990; FARIA; MENEGHETTI, 2007b). 


\section{2 "ENTÃO A PRIMEIRA COISA QUE TEM QUE HAVER DENTRO DE UMA DE UMA INSTITUIÇÃO DESTE TAMANHO, É CONFIANÇA”}

Essa categoria de análise demonstra o modo de comunicação e expressão da confiança no discurso dos gerentes como condição fundamental para a contratação e a permanência na IES, responsabilizando assim o docente pelas suas ações, desempenho e permanência. Essa é uma estratégia de adesão ao poder gerencialista nesse espaço. As verbalizações a seguir são exemplos disso:

Então, a primeira coisa que tem que haver dentro de uma de uma instituição deste tamanho, é confiança, porque se eu não confiar no outro, torna-se impossivel, ainda mais quando se trata de docente, ou você confia naquela pessoa que tá dentro da sala ou você não tem como saber eeexxxaaaatamente como as coisas tão acontecendo ali, porque ele tem nnnnnn maneiras de driblar todo processo [...] (Entrevistado 1).

Então, éhhh se eu não confiar que o meu professor vai ser exigente, vai ser na medida certa, que vai ter a postura que um professor precisa ter, éhhh ai num prec...éhhh ai num tem porquê contratá-lo (Entrevistado 1).

No primeiro trecho, o entrevistado 1 por meio da conjunção conclusiva "então", busca pontuar a importância da confiança dentro da instituição. Ressalta o "tamanho" da IES, com intenção de referir-se a dimensão espacial/física, ao crescimento no mercado local, ou também com a intenção de expressar subjetivamente a idealização, o ideal de perfeição e de expansão que atribui à essa IES (ENRIQUEZ, 1990). A estrutura textual que utiliza na verbalização, por meio da conjunção "se" (“se eu não confiar no outro”), expressa a confiança como condição para que o docente - que aparece na sentença como "outro" (mecanismo de substituição) e, é reforçado a partir da ênfase dada "ainda mais quando se trata de docente" - permaneça na IES, pois o contrário disso, ou seja, a falta da confiança "torna-se impossível" a sua permanência - "você não tem como saber eeexxxaaaatamente como as coisas tão acontecendo ali, porque ele tem nnnnnn maneiras de driblar todo processo".

A ênfase que o gerente dá ao enunciar a palavra "eeexxxaaaatamente" é a forma que encontra para chamar a atenção para a precisão e utilidade (ou seja, mecanismo de controle) 
que a confiança traz para a gestão da IES, já que o docente substituído pelo pronome "ele" nessa frase, tem "nnnnnn maneiras de driblar todo processo". Esse último trecho é marcado por duas metáforas: na primeira, "nnnnnn maneiras", o gerente faz uso da linguagem matemática por meio do símbolo " $n$ " que remete ao conjunto dos números naturais, de zero ao infinito; na segunda, "driblar todo processo", o gerente faz uso da metáfora a partir da palavra "driblar", que remete ao controle da bola no jogo de futebol, a fim de desviar-se do adversário. O uso dessas metáforas por parte do gerente expressa o quanto ele tem consciência da aptidão do professor de compreender todo o processo no qual está inserido na IES e de saber até como driblá-lo, em caso de sentir-se ameaçado. Sabendo disso, o gerente utiliza-se da confiança como estratégia de recalcamento - como "a primeira coisa" para se evitar qualquer comportamento transgressor (ENRIQUEZ, 2001; MOTTA, 1991) e alcançar o imaginário do docente a favor da dedicação integral à IES, não deixando emergir sua postura crítica (SIQUEIRA, 2009).

No segundo trecho, o entrevistado 1 confirma a instrumentalização da confiança como estratégia utilizada desde a contratação do docente (GAULEJAC, 2007). Novamente, por meio da conjunção "se", expressa a condição para que o docente seja contratado na IES. Seu tom de voz forte no momento de enunciação das palavras "exigente", "certa" e "postura", enfatizam as características que são requeridas dos docentes - "que um professor precisa ter" - para serem contratados. Meio sem jeito, como se não quisesse dizer diretamente expressão do ethos gerencialista -, o gerente busca palavras para amenizar a ideia de que se não forem obedecidas essas condições, não terá motivo para justificar a contratação de docentes para a IES (SIQUEIRA, 2009). A confiança, portanto, torna-se uma condição desde a contratação de docentes.

Esses trechos - o primeiro e o segundo do entrevistado 1 - expressam a responsabilização do docente pela sua contratação, desempenho e permanência, como estratégia de adesão ao poder gerencialista - exercido pelos gerentes nesse espaço (GAULEJAC, 2007).

$\mathrm{Na}$ perspectiva crítica, esses argumentos corroboram com a ideia de que a instrumentalização da confiança - em sua comunicação e expressão - tem sido mecanismo de controle subjetivo entre gerentes e docentes nas IES. Nota-se quanto a isso, que o gerente tende a afastar-se de instrumentos físicos de vigilância para trabalhar - produzir e promover discurso -, com elementos comunicativos da confiança, os quais têm o poder de influenciar pessoas e comportamentos (neste caso, docentes), ao ponto de confundir ideais na promoção de um ideal comum (SIQUEIRA, 2009), provocando "conflitos de racionalidade e 
intrapsíquicos", como a perda de identidade profissional, como ressaltado por Salimon e Siqueira (2012, p. 648).

\section{3 "ELE VAI LEVAR A BANDEIRA, VESTIR A CAMISA"}

Essa categoria analisa o modo de representação do discurso gerencial com intenção de mobilizar psicologicamente o docente à servidão livre e voluntária - com dedicação e amor à organização -, a partir do chamamento para "vestir a camisa" da IES. Quem ama, confia e se entrega ao objeto amado, e "vestir a camisa" é uma simbologia disso. Seguem verbalizações que exemplificam essas asserções:

Eu sempre formo uma equipe boa, eu tenho uma equipe de professores que eu formo, que eu sei que são pessoas que eu posso deixar que ele vai levar a bandeira, vestir a camisa, vão ser profissionais. Todo trabalho, acho que a diminuição do estresse no trabalho é a sua, é a equipe que cê formou pra trabalhar com você (Entrevistado 9).

Primeiro, espera uma equipe integrada, espera-se, espera-se uma equipe competente, integrada, competente, compromissada. Então eles vão refletir no grupo de professores a imagem do diretor (Entrevistado 9).

A primeira fala do entrevistado 9 começa com a narração do seu trabalho de formar uma equipe boa, a partir da intertextualidade manifesta com a expressão de sua voz ("eu" primeira pessoa do singular). Com tom de voz forte ao pronunciar e enfatizar "sempre formo", demonstra por meio do advérbio de intensidade "sempre" e do verbo "formo" no presente do indicativo, a constância na sua prática gerencial de estar atento a composição e formação da equipe de professores - "equipe boa" - no momento da fala proferida na entrevista. Percebe-se o discurso gerencial de promoção da confiança, por meio da instrumentalização da identificação do docente com a IES, já que o gerente espera que ele "vai levar a bandeira", "vestir a camisa" e "ser profissionais" (ENRIQUEZ, 1990; 1999). Ainda complementa, na sua segunda fala com palavras de um mesmo campo semântico ("integrada", "competente", "compromissada") o que espera da equipe, tanto para atender os seus interesses políticos como para atender aos objetivos da IES.

A partir desses enunciados do entrevistado 9, pode-se perceber que o mecanismo de promoção do discurso por meio da identificação é uma prática discursiva revestida de 
ideologia, intentando a identificação total, a confiança e o engajamento no alcance dos resultados para a IES (ENRIQUEZ, 1990; 1999; 2001). A identificação com a organização faz com que o indivíduo viva pôr e para a IES, o que pode evitar que ele perceba os conflitos e as contradições a que se submete (SIQUEIRA, 2009).

Pagès et al. (1987) situam que esse comportamento é uma devoção à organização. Nessa devoção a organização encarna um deus - um objeto de culto, transcendente a seus membros. Os trabalhadores compõem uma massa de fiéis que compartilham a mesma fé, crenças e dogmas. Enriquez (2001, p. 53) também compartilha dessa ideia; o autor afirma que "toda instituição, qualquer que seja sua natureza, se apropria de uma parte do divino", como uma forma de subjetivamente controlar seus trabalhadores.

Nota-se também, como a figura do gerente é mediadora desse processo, relembrando o discurso mítico organizacional de Faria e Meneghetti (2007a), acerca da colocação do gerente nesta posição de reverência - acima de uma pessoa comum - e de influenciador de pessoas em sua coletividade no âmbito da formação de uma "boa equipe" (Entrevistado 9). O próprio gerente (Entrevistado 9) confia na sua atuação para essa construção organizacional, contemplando a união de laços "fraternos" no campo organizacional em prol de uma missão "nobre" (FREITAS, 2000; SIQUEIRA, 2009). Lembrando que por trás dessa ideia de formação de "time", de "equipe boa", "integrada" como na fala do entrevistado 9, existe a influência de políticas de gestão de pessoas estritamente pautadas no incentivo ao desenvolvimento de relações de parceria e confiança entre gerentes e docentes, a fim de persuadir os docentes em prol do alcance dos objetivos e estratégias organizacionais (GAULEJAC, 2007; SIQUEIRA, 2009).

\section{CONSIDERAÇÕES FINAIS}

Este artigo alcançou o objetivo a que se propôs, o de analisar, sob um enfoque crítico e reflexivo, a confiança e sua instrumentalização no discurso de gerentes como modalidade de controle de docentes em Instituições de Ensino Superior (IES) privadas, à luz da ideologia gerencialista em tempos de avanço neoliberal. Foram entrevistados para isso, doze (12) gerentes de três (3) IES privadas em uma cidade localizada no estado de Minas Gerais, partindo do entendimento da promoção da confiança no discurso gerencial como uma forma de se embrenhar na subjetividade do docente.

Identificou-se, portanto, características do poder gerencialista que permitiram clarificar a instrumentalização da comunicação e expressão da confiança nas IES privadas no 
discurso de gerentes, devido eufemizarem as relações de controle, poder e dominação por meio de estratégias ideológicas como: a criação de uma relação mais próxima com os docentes em prol do engajamento (por meio da gestão de afetos); a responsabilização do docente pela sua contratação e permanência (por meio do recalcamento da postura crítica); e até a busca pela identificação total deles com a IES (por meio da idealização da instituição).

Como dito pelos próprios gerentes: "é quase liderança carismática" (Entrevistada 5), deixando claro a gestão de afetos (SIQUEIRA, 2009), em prol do engajamento dos docentes, uma vez que a confiança constrói relações e é também construída a partir desses vínculos, entre gerentes e docentes (FAIRCLOUGH, 2016); "então a primeira coisa que tem que haver dentro de uma de uma instituição deste tamanho, é confiança" (Entrevistado 1), denotando a responsabilização do docente pela sua contratação e permanência, sinal de eufemização do controle e recalcamento da postura crítica (ENRIQUEZ, 2001; MOTTA, 1991), com base no discurso de promoção da confiança; "ele vai levar a bandeira, vestir a camisa" (Entrevistado 9), indicando devoção, idealização e identificação com a IES e com os gerentes por meio da promoção do discurso da confiança, a fim de que o docente ame a IES e se envolva de corpo e alma à missão "nobre" nestas IES (ENRIQUEZ, 1990, 1999, 2001; FREITAS, 2000; MEDEIROS, 2017; MOTTA, 1991; PAGÈS et al., 1987).

Diante destas categorias, pode-se considerar que a confiança é a palavra-chave no repertório dessas organizações, com grande poder nas relações entre gerentes e docentes, como o de criar imaginários diversos a partir da sua instrumentalização nessa ordem de dupla natureza - pedagógica e administrativa destas IES privadas. Por meio da expressão de confiança, estimula-se o amor, o afeto, os vínculos subjetivos, o apego, a dedicação à IES e a crença do que é bom para a IES privada é bom também para o docente (ENRIQUEZ, 1999; FARIA; SCHMITT, 2007; FREITAS, 2000; GAULEJAC, 2007; MEDEIROS, 2017). Isso formaliza seu sistema de controle social e sua responsabilidade na conduta dos atores sociais e nas suas formas de raciocínio (MOTTA, [1979] 1993).

É possível pensar a comunicação e expressão da confiança como modismo gerencial de controle psíquico nos tempos neoliberais, instrumentalizada ideologicamente nos mainstreams organizacionais, devido o gerente pretender a partir dela estimular $\mathrm{o}$ desempenho do docente (SIQUEIRA, 2009). A confiança pode ser considerada como um meio de dominação passiva, sutil em seus intentos, mas voraz em seu poder de encantar o indivíduo em prol da adesão espontânea aos objetivos da organização (GAULEJAC, 2007).

Desse modo, há a inserção do indivíduo em uma massa acrítica, sob os auspícios do poder gerencialista, que o coloca como um bom servo da IES e não apenas dela, mas de 
determinada lógica que o aprisiona afetivamente. Isso é mais significativo ainda quando se fala do docente, que deveria estar imerso em um processo constante de reflexão quanto a seu papel no processo de mudança social, de transformação - do social e do organizacional - da perspectiva do indivíduo e não simplesmente, de forma, a assumir uma lógica que precariza e intensifica seu trabalho. Questiona-se então, de que docente estamos falando? E de que sujeito estamos falando? O que é o sujeito senão resistência, se não luta pelo que ele realmente quer para sua vida, que lhe dê significado? Qual é o espaço para se pensar em organizações educacionais que promovam a reflexão crítica, política das relações humanas, organizacionais e sociais no momento em que não há criticidade por parte destes próprios agentes organizacionais?

A principal contribuição teórica deste estudo foi o desenvolvimento do olhar crítico sobre o discurso gerencial, principalmente quanto à comunicação e expressão da confiança nas IES privadas (com fins lucrativos). Acredita-se que a realização deste estudo permitiu desvelar características do poder gerencialista racionalizadas e instrumentalizadas nesse ambiente.

Considera-se que a escassez de estudos teórico-críticos, a respeito da comunicação e expressão da confiança em periódicos nacionais da Administração foi fator limitador. Portanto, sugere-se como aprofundamento o desenvolvimento de estudos organizacionais com essa perspectiva, tanto de natureza teórica, como estudos teórico-empíricos nas mais diversas organizações, públicas e privadas, que investiguem como a falta de clareza na comunicação e expressão da confiança pode afetar negativamente o indivíduo.

\section{REFERÊNCIAS}

ANDRADE, S. M. de; FISCHER, A. L.; STEFANO, S. R. Confiança organizacional e interpessoal como uma dimensão de clima organizacional. Revista Base (Administração e Contabilidade) da UNISINOS, v. 12, n. 2, p. 155-166, 2015.

\section{ARANTES, I. C. da S. Concepções simbólico-discursivas do trabalho docente}

universitário na contemporaneidade. Tese (Doutorado em Administração) - Universidade Federal de Lavras, Lavras, 2015.

DEJOURS, C. A banalização da injustiça social. Tradução de Luiz Alberto Monjardim. Rio de Janeiro: Editora FGV, 2001.

DINIZ, B. A.; MARCONATTO, D. A. Confiança: um construto universal. Revista de Administraço Faces Journal, v. 11, n. 1, p. 35-55, 2011. 
ENRIQUEZ. E. Da horda ao Estado: psicanálise do vínculo social. Tradução de Teresa Cristina Carreteiro e Jacyara Nasciutti. Rio de Janeiro: Jorge Zahar Editor, 1990.

ENRIQUEZ. E. Instituições, Poder e “desconhecimento". In: ARAÚJO, J. N.;

CARRETEIRO, T.C (Orgs). Cenários sociais e abordagem clínica. Belo Horizonte: Fumec, p. 49-74, 2001.

ENRIQUEZ. E. Perda do trabalho, perda da identidade. In: NABUCO, M. R.; CARVALHO NETO, A (Orgs.). Relações de trabalho contemporâneas. Belo Horizonte: IRT PUC/Minas, p.69-83, 1999.

FACAS, E. P.; GHIZONI, L. D. As falácias do culto ao desempenho no mundo do trabalho. Trabalho (EN) cena, v. 3, n.2, p.01-02, 2018.

FAIRCLOUGH, N. Critical Discourse Analysis and the Marketization of Public Discourse: The Universities. Discourse \& Society, v. 4, n.2, p. 133-16, 1993.

FAIRCLOUGH, N. Critical discourse analysis: the critical study of language. London: Longman, 1999.

FAIRCLOUGH, N. Discurso e mudança social. Brasília: Ed. Universidade de Brasília, 2016.

FARIA, J. H. de.; MENEGHETTI, F. K. Discursos organizacionais. In: FARIA, J. H.de (Org). Análise Crítica das teorias e práticas organizacionais. São Paulo: Atlas, 2007a, p. 119-141.

FARIA, J. H. de.; MENEGHETTI, F. K. Sequestro da subjetividade. In: FARIA, J. H. de (Org.). Análise Crítica das teorias e práticas organizacionais. São Paulo: Atlas, 2007b, p. 45-68.

FARIA, J. H. de.; SCHMITT, E. C. Indivíduo, Vínculo e Subjetividade. In: FARIA, J. H.de. (Org.). Análise crítica de modelos das teorias e práticas organizacionais. São Paulo: Atlas, 2007, p.23-44.

FERNANDES, J. R. C. Relações de confiança na organização e no superior hierárquico e o seu impacto no empenhamento organizacional. Dissertação (Mestrado em Estudos de Gestão) - Escola de Economia e Gestão, Universidade do Minho, Braga - Portugal, 2014. FRANCHINI, F. et al. Desafios à docência no Ensino Superior em tempos neoliberais.

Revista Gestão \& Políticas Públicas, v. 6, n. 1, p. 118- 139, 2016.

FREITAS, M. E. Contexto social e imaginário organizacional moderno. Revista de Administração de Empresas, v. 40, n.2, p. 6-15, 2000.

GAULEJAC, V. Gestão como Doença social: Ideologia, poder gerencialista e fragmentação social. Tradução de Ivo Storniolo. Aparecida-SP: Ideias \&letras, 2007. 
GAULEJAC, V. Vivre dans une société paradoxante. Nouvelle revue de psychosociologie, v. 2, n. 24, p.27-40, 2017.

HANLON, G. Digging deeper towards capricious management: "Personal traits become part of the means of production.” Human Relations, v. 70, n.2, p. 168-184, 2016. HORTA, P.; DEMO, G.; ROURE, P. Políticas de gestão de pessoas, confiança e bem-estar: estudo em uma multinacional. Revista de Administração Contemporânea, v. 16, n. 4, p. 566-585, 2012.

KIDRON, A. Examining the Mediating Role of Commitment to the Supervisor in Employees’ Affective Commitment: Temporary Employees Versus Permanent Employees. Journal of Leadership \& Organizational Studies, 2018. Disponível em: https://journals.sagepub.com/doi/abs/10.1177/1548051818755635. Acesso em 14/04/2019. KODISH, S. Communicating Organizational Trust: An Exploration of the Link Between Discourse and Action. International Journal of Business Communication, vol. 54, Issue 4, p. 347-368, 2014.

MAGALHÃES, I. Prefácio. IN: FAIRCLOUGH, N. Discurso e mudança social. Brasília: Ed. Universidade de Brasília, 2016, p. 11-14.

MEDEIROS, B. N. Discurso organizacional em instituições de ensino superior privadas: uma análise crítica. Dissertação (Mestrado em Administração) - Universidade de Brasília, Brasília, 2017.

MELO, I. F. Análise do discurso e análise crítica do discurso: desdobramentos e intersecções.

Revista Eletrônica de Divulgação Científica em Língua Portuguesa, Lingüística e Literatura, vol. 05, n.11, p. 1-18, 2009.

MORO, C. V. M.; AMADOR, F. S. O trabalho da gestão: notas sobre poder e subjetividade.

Revista Psicologia Organizações e Trabalho, v. 15, n. 2, p. 201-211, 2015.

MOTTA, F. C. P. Controle Social nas organizações. (Revisitado por Isabella Gouveia de Vasconcelos e Thomaz Wood Jr.). Revista de Administração de Empresas, v. 33, n. 5, p. 68-87, 1993 [1979].

MOTTA, F. C. P. Organizações: vínculo e imagem. RAE-Revista de Administração de Empresas, v. 31, n. 3, p. 5-11, 1991.

NUNES, C. G. F.; SILVA, P. H. I. A sociologia clínica no Brasil. Revista Brasileira de Sociologia, vol. 6, n. 12, p. 181- 199, 2018.

PAGÈS, M. et al. O poder das organizações. Tradução de Maria Cecília Pereira Tavares.1 ed. São Paulo: Atlas, 1987. 
SALIMON, M. I.; SIQUEIRA, M. V. S. Ideologia Gerencialista e Subjetividade no terceiro setor. Revista de Administração da Universidade de São Paulo, v.48, n.4, p.643-657, 2013.

SEVERINO, A. J. Expansão do Ensino Superior: Contextos, desafios, possibilidades. Revista da Avaliação da Educação Superior, v. 14, n. 2, p. 253-266, 2009.

SIQUEIRA, M. V. S. Gestão de pessoas e discurso organizacional: crítica à relação indivíduo-empresa nas organizações contemporâneas. Curitiba: Juruá Editora, 2009.

TASSELLI, S. Love and Organization Studies: Moving beyond the Perspective of Avoidance. Organization Studies, 2018. Disponível em:

https://journals.sagepub.com/doi/10.1177/0170840617747924 Acesso em: 10/04/2019. ZANINI, M. T. F.; MIGUELES, C. P. O papel mediador entre confiança e desempenho organizacional. Revista de Administração da Universidade de São Paulo, v. 49, n. 1, p. 45-58, 2014.

ZANINI, M. T. F.; SANTOS, M. C. C. dos; LIMA, D. de F. P. A influência do estilo de liderança consultivo nas relações de confiança e comprometimento no Batalhão de Operações Policiais Especiais do Rio de Janeiro. Revista de Administração da Universidade de São Paulo, v. 50, n.1, p. 105-120, 2015.

XIMENES, Leandro Santos. Ideologia gerencialista versus trabalho docente: um diagnóstico pautado no discurso de docentes do ensino superior das esferas públicas e privadas. Dissertação (Mestrado em Administração). Niterói: Universidade Federal Fluminense, 2015 (primeira versão). 